\title{
CLASSES OF UNIFORMLY STARLIKE AND CONVEX FUNCTIONS
}

\author{
SAEID SHAMS, S. R. KULKARNI, and JAY M. JAHANGIRI
}

Received 1 February 2004

\begin{abstract}
Some classes of uniformly starlike and convex functions are introduced. The geometrical properties of these classes and their behavior under certain integral operators are investigated.
\end{abstract}

2000 Mathematics Subject Classification: 30C45, 30C50.

1. Introduction. Let $A$ denote the class of functions of the form $f(z)=z+\sum_{n=2}^{\infty} a_{n} z^{n}$ which are analytic in the open unit disk $U=\{z:|z|<1\}$. A function $f$ in $A$ is said to be starlike of order $\beta, 0 \leq \beta<1$, written as $f \in S^{*}(\beta)$, if $\operatorname{Re}\left[\left(z f^{\prime}(z)\right) /(f(z))\right]>\beta$. A function $f \in A$ is said to be convex of order $\beta$, or $f \in K(\beta)$, if and only if $z f^{\prime} \in S^{*}(\beta)$.

Let $\operatorname{SD}(\alpha, \beta)$ be the family of functions $f$ in $A$ satisfying the inequality

$$
\operatorname{Re}\left\{\frac{z f^{\prime}(z)}{f(z)}\right\}>\alpha\left|\frac{z f^{\prime}(z)}{f(z)}-1\right|+\beta, \quad z \in U, \alpha \geq 0,0 \leq \beta<1 .
$$

We note that for $\alpha>1$, if $f \in \operatorname{SD}(\alpha, \beta)$, then $z f^{\prime}(z) / f(z)$ lies in the region $G \equiv G(\alpha, \beta) \equiv$ $\{w: \operatorname{Re} w>\alpha|w-1|+\beta\}$, that is, part of the complex plane which contains $w=1$ and is bounded by the ellipse $\left(u-\left(\alpha^{2}-\beta\right) /\left(\alpha^{2}-1\right)\right)^{2}+\left(\alpha^{2} /\left(\alpha^{2}-1\right)\right) v^{2}=\alpha^{2}(1-\beta)^{2} /\left(\alpha^{2}-1\right)^{2}$ with vertices at the points $((\alpha+\beta) /(\alpha+1), 0),((\alpha-\beta) /(\alpha-1), 0),\left(\left(\alpha^{2}-\beta\right) /\left(\alpha^{2}-1\right)\right.$, $\left.(\beta-1) / \sqrt{\alpha^{2}-1}\right)$, and $\left(\left(\alpha^{2}-\beta\right) /\left(\alpha^{2}-1\right),(1-\beta) / \sqrt{\alpha^{2}-1}\right)$. Since $\beta<(\alpha+\beta) /(\alpha+1)<$ $1<(\alpha-\beta) /(\alpha-1)$, we have $G \subset\{w: \operatorname{Re} w>\beta\}$ and so $\operatorname{SD}(\alpha, \beta) \subset S^{*}(\beta)$. For $\alpha=1$ if $f \in \mathrm{SD}(\alpha, \beta)$, then $z f^{\prime}(z) / f(z)$ belongs to the region which contains $w=2$ and is bounded by parabola $u=\left(v^{2}+1-\beta^{2}\right) / 2(1-\beta)$.

Using the relation between convex and starlike functions, we define $\operatorname{KD}(\alpha, \beta)$ as the class of functions $f \in A$ if and only if $z f^{\prime} \in \operatorname{SD}(\alpha, \beta)$. For $\alpha=1$ and $\beta=0$, we obtain the class $\mathrm{KD}(1,0)$ of uniformly convex functions, first defined by Goodman [1]. Rønning [3] investigated the class $\mathrm{KD}(1, \beta)$ of uniformly convex functions of order $\beta$. For the class $\mathrm{KD}(\alpha, 0)$ of $\alpha$-uniformly convex function, see [2]. In this note, we study the coefficient bounds and Hadamard product or convolution properties of the classes $\operatorname{SD}(\alpha, \beta)$ and $\mathrm{KD}(\alpha, \beta)$. Using these results, we further show that the classes $\operatorname{SD}(\alpha, \beta)$ and $\operatorname{KD}(\alpha, \beta)$ are closed under certain integral operators.

2. Main results. First we give a sufficient coefficient bound for functions in $\operatorname{SD}(\alpha, \beta)$.

THEOREM 2.1. If $\sum_{n=2}^{\infty}[n(1+\alpha)-(\alpha+\beta)]\left|a_{n}\right|<1-\beta$, then $f \in \operatorname{SD}(\alpha, \beta)$. 
Proof. By definition, it is sufficient to show that

$$
\left|\frac{z f^{\prime}(z)}{f(z)}-(1+\beta)-\alpha\right| \frac{z f^{\prime}(z)}{f(z)}-1||<\left|\frac{z f^{\prime}(z)}{f(z)}+(1-\beta)-\alpha\right| \frac{z f^{\prime}(z)}{f(z)}-1|| .
$$

For the right-hand side and left-hand side of (2.1) we may, respectively, write

$$
\begin{aligned}
R & =\left|\frac{z f^{\prime}(z)}{f(z)}+(1-\beta)-\alpha\right| \frac{z f^{\prime}(z)}{f(z)}-1|| \\
& =\frac{1}{|f(z)|}\left|z f^{\prime}(z)+(1-\beta) f(z)-\alpha e^{i \theta}\right| z f^{\prime}(z)-f(z)|| \\
& \geq \frac{1}{|f(z)|}\left[(2-\beta)|z|-\sum_{n=2}^{\infty}(n+1-\beta)\left|a_{n}\right||z|^{n}-\alpha \sum_{n=2}^{\infty}(n-1)\left|a_{n}\right||z|^{n}\right] \\
& >\frac{|z|}{|f(z)|}\left[2-\beta-\sum_{n=2}^{\infty}(n+1-\beta+n \alpha-\alpha)\left|a_{n}\right|\right],
\end{aligned}
$$

and similarly

$$
L=\left|\frac{z f^{\prime}(z)}{f(z)}-(1+\beta)-\alpha\right| \frac{z f^{\prime}(z)}{f(z)}-1||<\frac{|z|}{|f(z)|}\left[\beta+\sum_{n=2}^{\infty}(n-1-\beta+n \alpha-\alpha)\left|a_{n}\right|\right]
$$

Now, the required condition (2.1) is satisfied, since

$$
R-L>\frac{|z|}{|f(z)|}\left[2(1-\beta)-2 \sum_{n=2}^{\infty}[n(1+\alpha)-(\alpha+\beta)]\left|a_{n}\right|\right]>0 .
$$

The following two theorems follow from the above Theorem 2.1 in conjunction with a convolution result of Ruscheweyh and Sheil-Small [5] and the already discussed relation between the classes $\operatorname{SD}(\alpha, \beta)$ and $\operatorname{KD}(\alpha, \beta)$.

THEOREM 2.2. If $\sum_{n=2}^{\infty} n[n(1+\alpha)-(\alpha+\beta)]\left|a_{n}\right|<1-\beta$, then $f \in \operatorname{KD}(\alpha, \beta)$.

THEOREM 2.3. The classes $\mathrm{SD}(\alpha, \beta)$ and $\operatorname{KD}(\alpha, \beta)$ are closed under Hadamard product or convolution with convex functions in $U$.

From Theorem 2.3 and the fact that

$$
F(z)=\frac{1+\lambda}{z^{\lambda}} \int_{0}^{z} t^{\lambda-1} f(t) d t=f(z) * \sum_{n=1}^{\infty} \frac{1+\lambda}{n+\lambda} z^{n}, \quad \operatorname{Re} \lambda \geq 0,
$$

we obtain the following corollary upon noting that $\sum_{n=1}^{\infty}((1+\lambda) /(n+\lambda)) z^{n}$ is convex in $U$.

COROLlary 2.4. If $f$ is in $\operatorname{SD}(\alpha, \beta)$ or $\mathrm{KD}(\alpha, \beta)$, so is $F(z)$ given by (2.5).

Similarly, the following corollary is obtained for

$$
G(z)=\int_{0}^{z} \frac{f(t)-f(\mu t)}{t(1-\mu)} d t=f(z) *\left(z+\sum_{n=2}^{\infty} \frac{1-\mu^{n}}{n(1-\mu)} z^{n}\right), \quad|\mu| \leq 1, \mu \neq 1 .
$$


Corollary 2.5. If $f$ is in $\operatorname{SD}(\alpha, \beta)$ or $\mathrm{KD}(\alpha, \beta)$, so is $G(z)$ given by (2.6).

We observed that if $\alpha>1$ and if $f \in \operatorname{SD}(\alpha, \beta)$, then $\left(z f^{\prime}(z) / f(z)\right)_{z \in U} \subset E$, where $E$ is the region bounded by the ellipse $\left(u-\left(\alpha^{2}-\beta\right) /\left(\alpha^{2}-1\right)\right)^{2}+\left(\alpha^{2} /\left(\alpha^{2}-1\right)\right) v^{2}=$ $\alpha^{2}(1-\beta)^{2} /\left(\alpha^{2}-1\right)^{2}$ with the parametric form

$$
w(t)=\frac{\alpha^{2}-\beta}{\alpha^{2}-1}+\frac{\alpha(1-\beta)}{\alpha^{2}-1} \cos t+\frac{i(1-\beta)}{\sqrt{\alpha^{2}-1}} \sin t, \quad 0 \leq t<2 \pi .
$$

Thus for $\alpha>1$ and $z$ in the punctured unit disk $U-\{0\}$, we have $f \in \operatorname{SD}(\alpha, \beta)$ if and only if $z f^{\prime}(z) / f(z) \neq w(t)$ or $z f^{\prime}(z)-w(t) f(z) \neq 0$. By Ruscheweyh derivatives (see [4]), we obtain $f \in \operatorname{SD}(\alpha, \beta)$, if and only if $f(z) *\left[z /(1-z)^{2}-w(t)(z /(1-z))\right] \neq 0$, $z \in U-\{0\}$. Consequently, $f \in \operatorname{SD}(\alpha, \beta), \alpha>1$, if and only if $f(z) * h(z) / z \neq 0, z \in U$ where $h$ is given by the normalized function

$$
h(z)=\frac{1}{1-w(t)}\left[\frac{z}{(1-z)^{2}}-w(t) \frac{z}{1-z}\right]
$$

and $w$ is given by (2.7). Conversely, if $f(z) * h(z) / z \neq 0$, then $z f^{\prime}(z) / f(z) \neq w(t)$, $0 \leq t<2 \pi$. Hence $\left(z f^{\prime}(z) / f(z)\right)_{z \in U}$ lie completely inside $E$ or its compliment $E^{c}$. Since $\left(z f^{\prime}(z) / f(z)\right)_{z=0}=1 \in E,\left(z f^{\prime}(z) / f(z)\right)_{z \in U} \subset E$, which implies that $f \in \operatorname{SD}(\alpha, \beta)$. This proves the following theorem.

THEOREM 2.6. The function $f$ belongs to $\operatorname{SD}(\alpha, \beta), \alpha>1$, if and only if $f(z) * h(z) /$ $z \neq 0, z \in U$ where $h(z)$ is given by (2.8).

\section{REFERENCES}

[1] A. W. Goodman, On uniformly convex functions, Ann. Polon. Math. 56 (1991), no. 1, 87-92.

[2] S. Kanas and A. Wiśniowska, Conic domains and starlike functions, Rev. Roumaine Math. Pures Appl. 45 (2000), no. 4, 647-657.

[3] F. Rønning, On starlike functions associated with parabolic regions, Ann. Univ. Mariae CurieSkłodowska Sect. A 45 (1991), 117-122.

[4] St. Ruscheweyh, New criteria for univalent functions, Proc. Amer. Math. Soc. 49 (1975), 109115.

[5] St. Ruscheweyh and T. Sheil-Small, Hadamard products of Schlicht functions and the PólyaSchoenberg conjecture, Comment. Math. Helv. 48 (1973), 119-135, Corrigendum in Comment. Math. Helv. 48 (1973), 194.

Saeid Shams: Department of Mathematics, Fergusson College, Pune - 411004, India

S. R. Kulkarni: Department of Mathematics, Fergusson College, Pune - 411004, India E-mail address: ku7karni_ferg@yahoo.com

Jay M. Jahangiri: Department of Mathematics, Kent State University, Burton, OH 44021-9500, USA

E-mail address: jay@geauga.kent.edu 


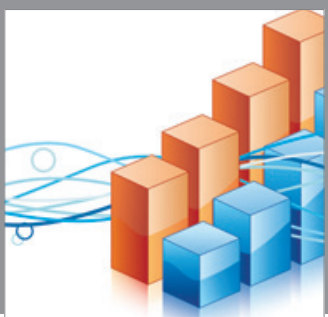

Advances in

Operations Research

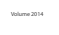

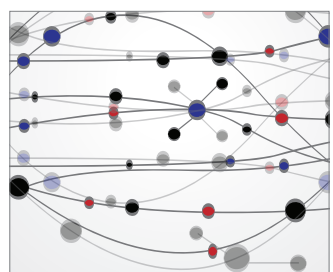

\section{The Scientific} World Journal
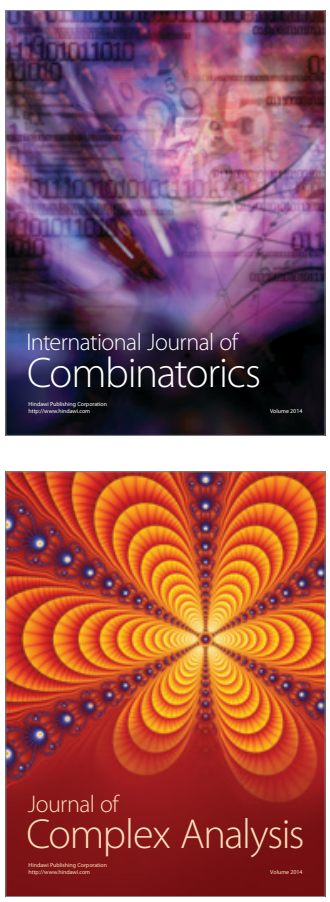

International Journal of

Mathematics and

Mathematical

Sciences
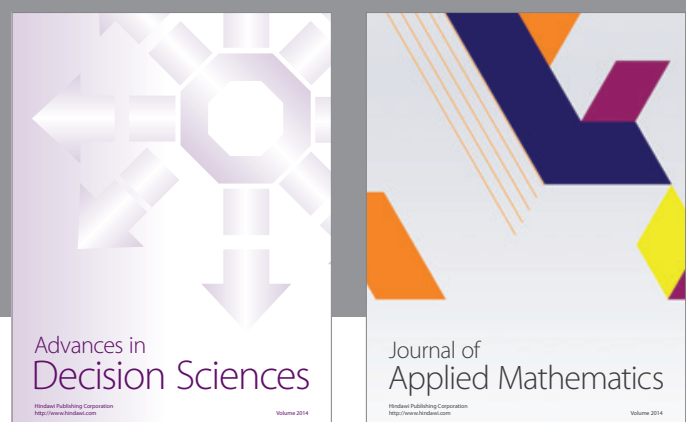

Journal of

Applied Mathematics
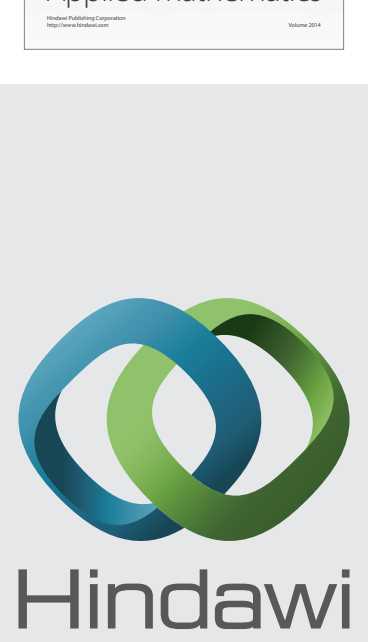

Submit your manuscripts at http://www.hindawi.com
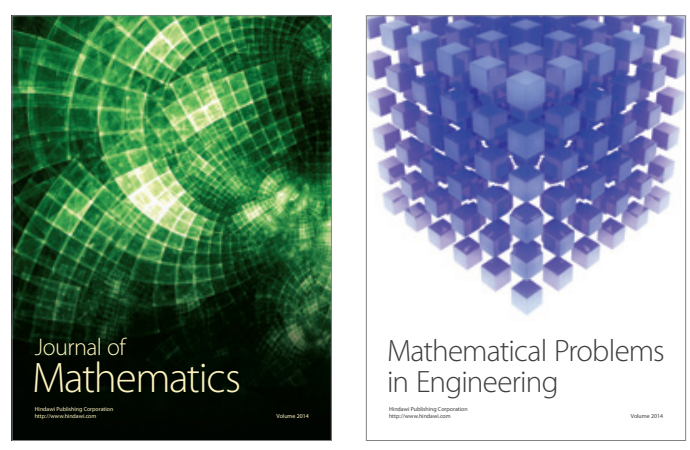

Mathematical Problems in Engineering
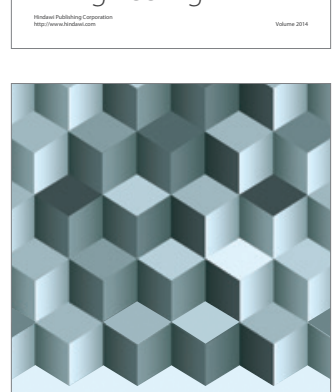

Journal of

Function Spaces
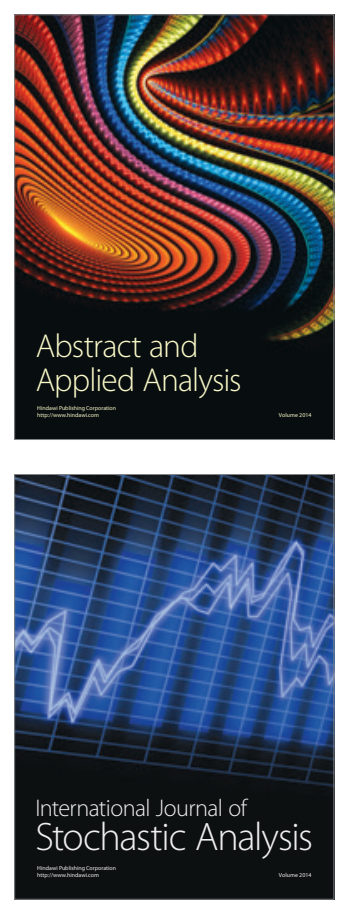

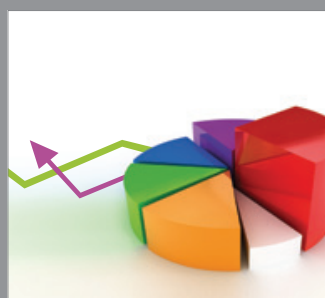

ournal of

Probability and Statistics

Promensencen
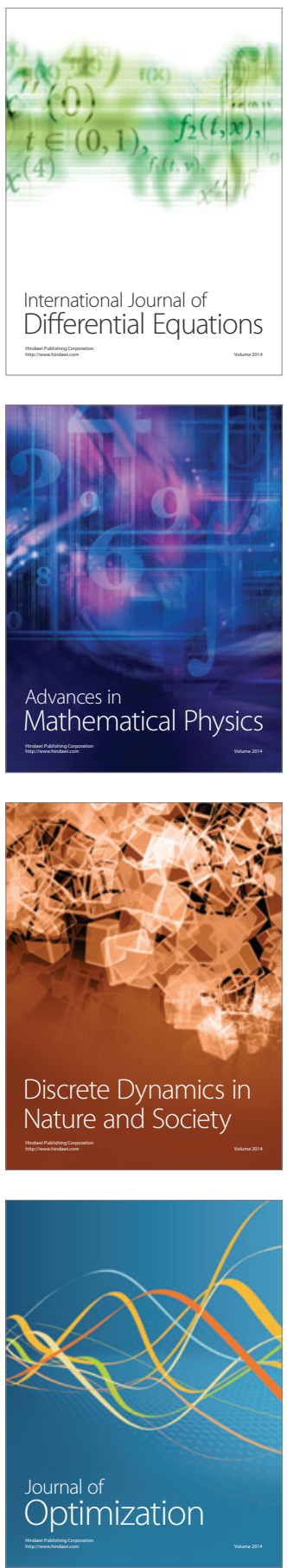